\title{
Impact of Chinese Foreign Direct Investment in Nigerian Oil Sector
}

\author{
Abdulrasheed Akanni Okoya ${ }^{1}$ Prof. Du Xuejun ${ }^{2}$ \\ School of Economics and Management, \\ Zhejiang University of Science and Technology; Hangzhou-CN
}

\begin{abstract}
The purpose of this study is to investigate the effects of foreign direct investment by Chinese investors in the oilSector in Nigeria. This study explores the impact of foreign direct investment on the Nigeria oil sector. The secondary data originates from 2018. The analysis results show that China's opening to direct trade in Nigeria's oil sector has consequences. In addition, there is no significant impact on Nigeria's oil market size and infrastructural development. This result supports the trend of results from similar literature studies. Based on these results, the study recommends paying particular attention to the introduction of new promotional rules necessary to support the country's economic objectives. The aim is to improve the flow of economic growth and direct investment into Nigeria. The main conclusion of the analysis is that Nigeria, as a country, has not yet deduced its potential (taking into account available resources and size of the market) in order to attract foreign investment.
\end{abstract}

Keywords: Foreign Direct Investment, Nigeria, Oil Sector, Economics, China

DOI: $10.7176 / \mathrm{JESD} / 11-16-03$

Publication date:August $31^{\text {st }} 2020$

\subsection{INTRODUCTION}

Oil-rich Nigeria has been abandoned due to political instability, corruption, lack of infrastructure and macroeconomic mismanagement that has hampered economic development and growth. The government is interested in improvements in all these areas. This has generated interest in foreign direct investment as a means of achieving economic growth.

According to Nwankwo (2006), the model creates jobs and acts as a means of technology transfer, provides excellent management skills and techniques, facilitates local business access to international markets and increases product diversity. Ayanwale (2007) stated that most countries are trying to attract FDI because of the benefits recognized as an economic development tool. This view is supported by some studies, which stated that FDI is the driving force of economic growth and development in Africa, where its needs can only be underlined. While the potential importance of attracting FDI in the development process cannot be overestimated, two key issues related to foreign direct investment are crucial. First, what are the determinants of FDI in a typical host country? Second, are these factors under the control of the host country and not subject to manipulation by the investors, in this case China? These topics are widely discussed in the literature, but the gap still exists mainly in empirical analysis. For example, tax incentives should be encouraged if there is a mutual benefit for both the host country and direct and direct access rights. The literature confirms the fact that FDI has impact on the host country, it comprises increase revenues without sacrificing the economic benefits of foreign direct investment. However, if the foreign direct investment (FDI) with taxes decreases, the host country should take into account the balance between the potential profits from tax increases and the economic costs of deterring foreign direct investment (FDI).

Thus, Nwankwo (2006), Edmiston, Mudd, Valev (2003) believed that, the government often tries to attract

Foreign Direct Investment (FDI) by offering tax incentives to companies, although there seems to be agreement in the literature that the level of tax rates in the host countries is an important factor in explaining patterns between FI countries. More limited evidence of tax incentives suggests that the impact is small or inconsistent in most countries. Edmiston, Mudd, Valev (2003), explained that there is no complete history because some European companies will receive a loss of tax incentives because they would still invest without them. They argued that offering tax incentives can sometimes reduce the level of foreign direct incentives in the host country when the tax burden is on companies that do not receive incentives when other companies receive incentives. This would be the case if the host country provided a certain level of service, the costs of which would be increased in the number of operators. Foreign Direct Investment (FDI) attracts many factors, such as the availability of natural resources like oil, for which Nigeria is equipped. According to Ayanwale (2007), Nigeria has a large market size, the availability of attractive raw materials and little oil, which translates into enormous benefits for FDI. Albaladejo (2003) believed that Nigeria's industrial performance, despite its rich natural resources, Africa's largest domestic market and abundant and cheap labour, was a major disappointment. He said the country was dangerously reliant on oil as the only way to get foreign currency, hence the Chinese foreign direct investment into the oil sector.

\subsection{Motivation of the Study}

This research's main objective is to access the impacts of Chinese Foreign Direct Investment (FDI) in Nigeria oil 
sector, in order to conduct overall analysis of impact of Chinese FDI on the development of this sector and the country as whole.

\subsection{LITERATURE REVIEW}

\subsection{Foreign Direct Investment FDI}

Foreign direct investment is a process in which individuals acquire property in a country in order to gain control over the production, distribution and other activities of a company abroad (Moosa, 2002). The OECD reference (OECD, 1996) defines foreign direct investment as the objective of achieving a permanent share of a resident unit in a single economy (direct investor) in an in-company based on an economy other than the investment economy (direct investment company)." There are different definitions of Foreign Direct Investment (FDI) which are not significantly different, generally considered to be a real phenomenon or an economic phenomenon (Moosa, 2002). On the basis of the financial basis, operational programmes are defined as follows:

- the nature of the cross-border transfer of investments where foreign financial party interest rate differences between the two economies, as the country with higher interest rates is more attractive to foreign companies; - External provision of assets to the economy - Foreign direct investment shows the amount of foreign investment in the country over a certain period of time, as stated in the balance of payments.

- ways of reducing and eradicating poverty in the end through economic growth in developing countries and Africa, in particular with regard to the UN Millennium Development Goals (Asia, 2006);

However, only in terms of economic conditions does it appear to underestimate the extent to which producers and UCITS are linked to a number of production factors. This means that, although financial flows are the main component of FDI, this may not be the most important factor. According to Moosa (2002), the specificity of foreign direct investment compared to other forms of international investment is also its role in management and decisionmaking policy. Therefore, the description of Foreign Direct Investment (FDI) accommodation as a purely economic phenomenon seems to underestimate this aspect.

\subsection{Theoretical Framework}

Several economic theories wanted to explain Foreign Direct Investment (FDI) in the country in both positive and negative terms. Economic theories such as neo-classical theory, development model theory are considered fundamental talking points.

First of all, the neoclassical perspective is based on a fundamental principle of the economy, which suggests that economic growth requires investment in the form of long-term commitments (Adams, 2009). This simply means that this theory leads to a better relationship between the direct input and the economic development of any society, especially in some developing countries.

Second part also focused on the various ways in which foreign direct investment by multinationals disrupts the economies of developing countries. Some researchers of this theory believed that the factors of confusion included the displacement of national companies, the increase in unemployment associated with the use of capitalintensive technology and a significant loss of political dominance (Umah, 2007). It has also been argued that direct investment is more exploitative and imperialist, so that the host country depends entirely on its country of origin and capital. (Anyanwu, 1993).

This theory from the analytical point could be discovered to create negative relationships between foreign direct investment and developing countries. The theory is very clear such that, the economic participation of developed countries in developing countries within multinationals and directly in the target fund will surely fall back to the economic disadvantages of developing countries.

The next theory to be considered is the endogenous theory of the development model. While neoclassical theory assumes that long-term investment is a key factor in the development of the country's economy, the theory of the internal development model has found that physical investment is not the goal of the country's economic development, but the efficiency of these investments. Economic models of internal development were used to assess the impact of direct business networks on economic development through technological diversification. (Baro, 1991). Romer (1990) argues that foreign direct investment promotes economic development by strengthening human capital, which is the most important factor in regional development efforts; Grossman and the Helpman (1991) stress that increased competition and innovation will lead to technological progress and productivity growth, thus supporting long-term economic growth.

According to Aremu (2003), the theory of addiction is that poor developing countries are due to: imperial negligence; over-reliance on primary products, such as the export of foreign investors to industrialized countries, in particular by transferring control pricing mechanisms on foreign enterprises into key economic sectors leading to the production of domestic enterprises; the implementation of inadequate technologies in developing countries by introducing an international division of labour at the expense of provincial development hinders the development of an independent development strategy for domestic technologies and domestic investors by disrupting the national workforce with discriminatory wages and dependence on foreign aid, which has largely 
exacerbated corruption.

\subsection{Foreign Direct Investment (FDI) Denunciation}

This was a central discussion without a special meeting of discipline experts on damage analysis and well-offered FDIs for developing economies. Researchers are examining failed attempts by the FDI to improve host economies as host countries diverge to improve their main infrastructure determinants. Research has shown that most developing countries, including Nigeria, do not use Foreign Direct Investment FDI significantly as a source of external financing to the economy due to unhinged climate investment and the attitude of host countries (Asia, 2002; Balasubramanyam, 2001. While some writers talk about the negative effects of EFDIs with the decline of host countries, they have only highlighted the various positive effects for host countries, who themselves discuss the fact that policymakers in many countries are working to create all kinds of incentives (e.g. export processing zones and tax incentives) to attract FDIs because they want to have a positive impact on local economic development.

\subsection{THE IMPACT OF FOREIGN DIRECT INVESTMENT ON THE NIGERIA}

Foreign direct investment (FDI) is a direct investment into business activities in a country by an individual or company of another country, either by acquiring a company in the target country or by increasing extant business operations in that country (Wikipedia, 2014). FDI can be expressed in both broad and narrow perspectives. In general, it includes "mergers and acquisitions, construction of new assets, reinvestment of profits from foreign operations and domestic loans". In a narrow sense, the FA means building new facilities. This paper focuses on how foreign direct investment can improve technology transfer in Nigeria's oil sector and capital inflows from abroad. It is true that Nigeria receives dividends from the creation of free zones. This is because in 2009 , $\$ 1.50$ was the year of the world of 2016 over the years, Nigeria has become an import-dependent country. But now a paradigm shift is taking place, which began with a plan for an industrial revolution in Nigeria based on the creation of oil and gas-free zones (Aganga, 2013). With the influx of money in Nigeria's economy, the country now has a high-growth, high-income environment. In addition, Nigeria ranks fourth in the world with an average yield of $35.5 \%$ above the global average. This paper examines the impact of foreign direct investment on Nigeria's oil sector in 2018-2020.

\section{Crude Oil Production}

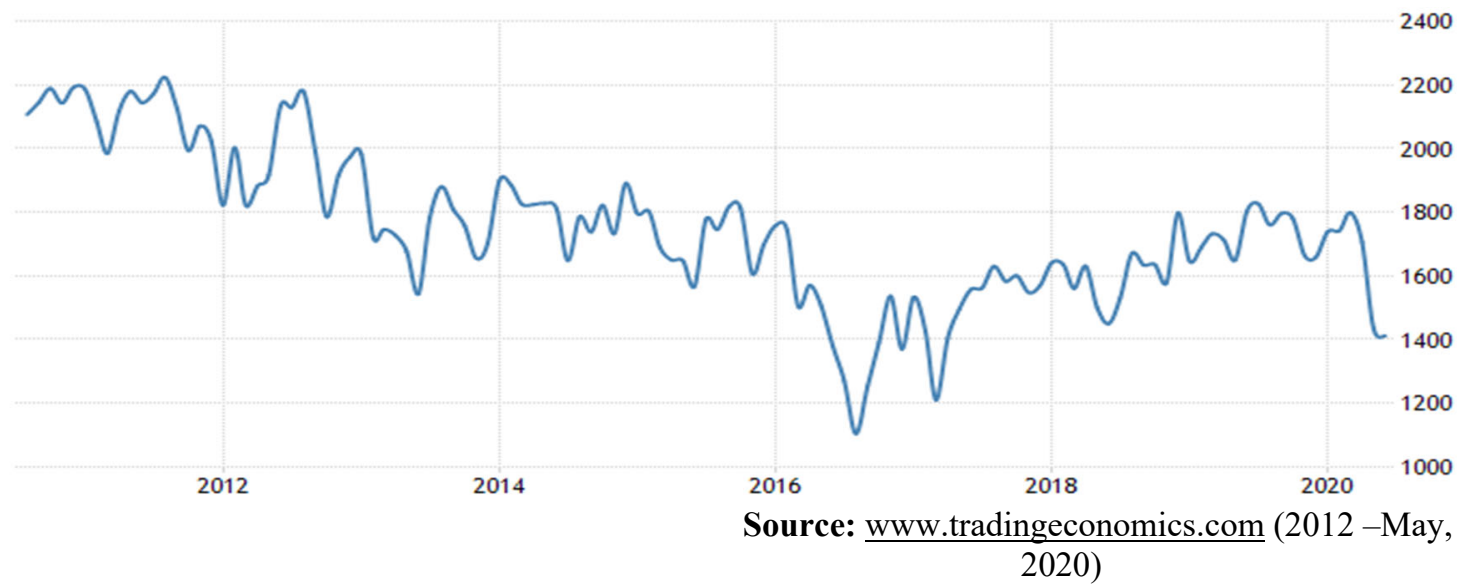

Figure. 1: Nigeria Crude Oil Production

Nigeria's oil production dropped from BBL/D/1K in June to BBL/D/1K in 2020. Global macro models and analysts' expectations suggest that Nigeria's oil production is expected to reach $\mathrm{BBL} / \mathrm{D} / 1 \mathrm{~K}$ by the end of this quarter. The most recent figures, such as Nigerian oil production, previous reports, historical ups and downs, shortterm forecasts and long-term forecasts, economic calendars, consensus surveys and news. Nigerian oil production, which is a value, historical data and graph, was last updated in May 2020. 


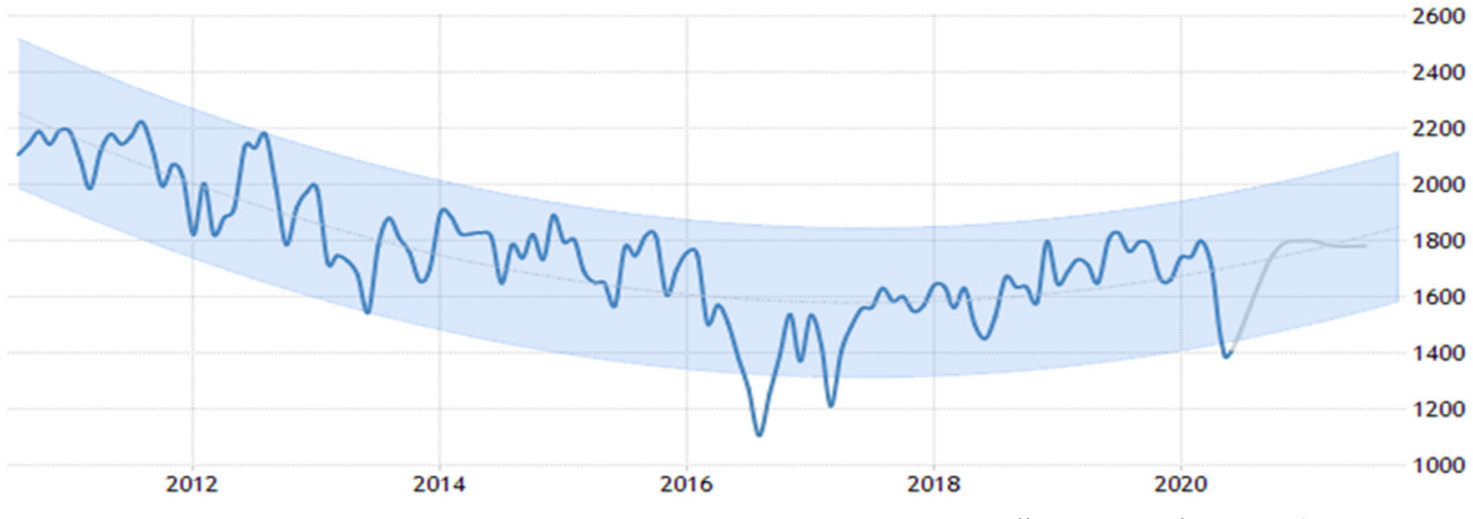

Source: $\underline{\text { www.tradingeconomics.com }}(2012-$ May, 2020)

Figure 2: Nigerian Crude oil production forecast

Nigeria's oil production is expected to be $1,780.00$ in 12 months. In the longer term, oil production in Nigeria is expected to increase by $20 \%$ by 2021 .

Source: www.tradingeconomics.com (2012 -

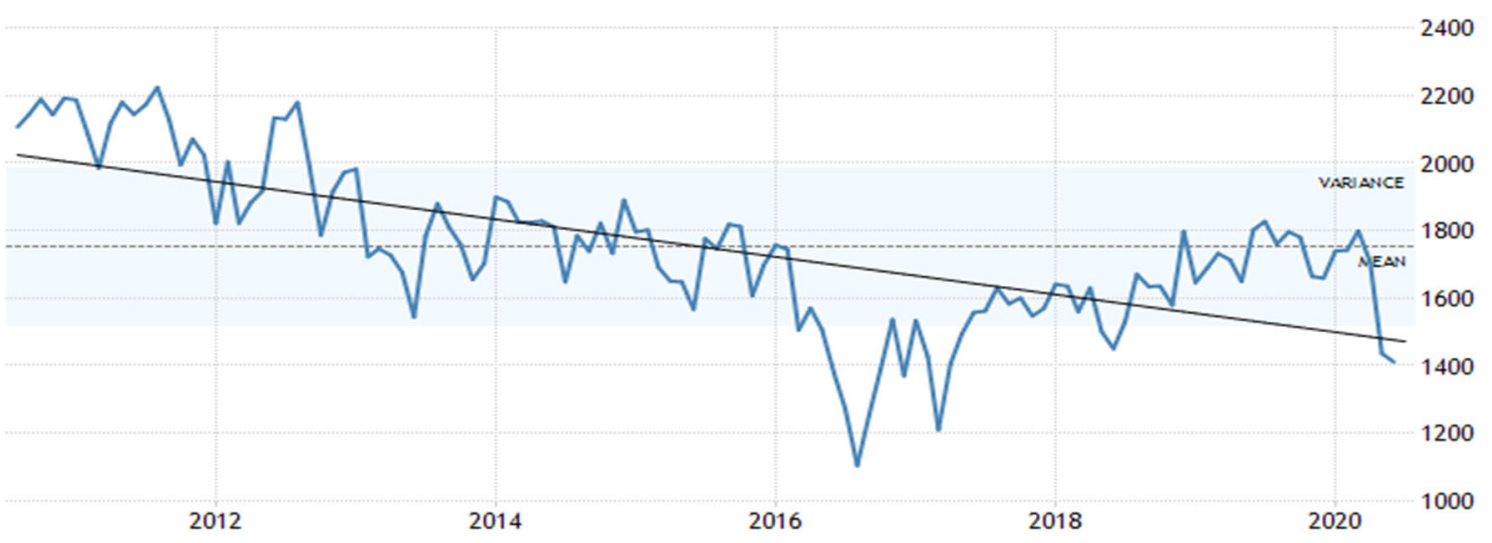

May, 2020)

Figure 3: Nigerian Crude Oil Production Forecast

Another reported value - Nigerian crude oil production - in addition to previous releases, historical high and low, short-term expectations and long-term outlook, economic calendar, consensus survey and news. The latest update to Nigerian crude oil production - values, historical data and charts - was last updated in August 2020.

\section{China Imports from Nigeria of Crude Oil}

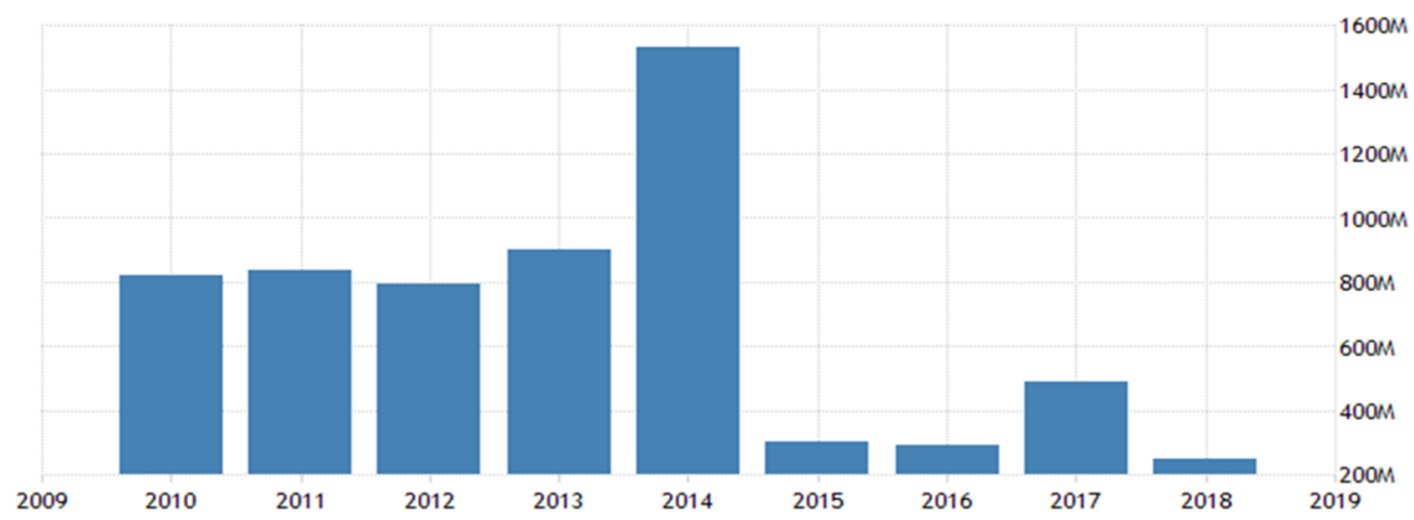

Figure 4: China Imports from Nigeria of Crude Oil

Source: www.tradingeconomics.com $(2009-2019)$

In 2018, Chinese crude oil imports from Nigeria were USD 250.06 million, according to the Database for International Trade. Nigeria's economy grew at an annual rate of $1.87 \%$ in the first quarter of 2020 . This was the slowest pace of economic expansion since the third quarter of 2018, the impact of the disruption, particularly in 
the youth sector ( $1.55 \%$ vs. $2.27 \%$ in the fourth quarter), due to the decrease in the impact on internal trade $(-2.82 \%$ versus. $0.58 \%$ ), housing and food services $(-2.99 \%$ vs. $2.05 \%)$, public administration $(-8.72 \%$ vs. $0.06 \%)$, administrative and support services $(-1.9 \%$ vs. $1.27 \%)$, the very important oil sector lost its steam $(5.06 \%$ vs. $6.36 \%)$.

\subsection{DISCUSSION OF THE FINDINGS}

\subsection{Finding}

The development framework, which includes six basic variables that can support sustainable economic growth, if affected positively, contributes to the evaluation of Nigeria's prospects. In order to achieve sustainable development and development, significant progress needs to be made in policy-making, institutions, human capital, entrepreneurship, culture and governance. Foreign direct investment in Nigeria averaged 950.29 million in the period 1990 - 2019, reaching a record of $\$ 3,084.90$ million in the fourth quarter of 2012. Inflows of foreign investment into Nigeria's oil and gas Industry 2020. In the first year of 2020, the Commission noted that NBS also stated that 2020. NBS also said it would be the first time in 2019 that the UK would be fined for $\$ 100.000$.

Nigeria's elite authorities preferred China's participation, but China's strongest leadership was observed. African leaders have dictated to the Chinese what development projects they want to implement, but the biggest challenge remains the absence of genuine leaders willing to stand up and express a long-term development strategy that adequately meets the needs of most Nigerian citizens. "Widespread corruption in Nigeria has also proven a serious cultural obstacle to be overcome if Nigeria is able to exploit its claims against China.

\subsubsection{Policy Choices:}

In addition to the data collected, they suggest that African politicians in general, and Nigerians in particular, including national and local officials, do not pursue policies that will have the greatest possible impact on longterm economic growth for a wide range of citizens. While many of the current policies are likely to benefit Nigeria and will make a significant contribution to economic development in some areas, the policies seem to ignore the fact that significant long-term needs, key populations, and the target group of key sectors leading to a diversified economy are ignored.

For example, while evidence shows that many of Nigeria's benefits can be achieved through agriculture by promoting some of the same policies that have benefited China's industrialization, a robust agricultural development program remains to be seen. While development models suggest that a strong middle class is the backbone of growth, the government has not focused on providing basic needs to a broad population.

4.2.3 Human Capital:

The case study also suggests that transferring technological skills and training from Chinese to Nigerian citizens tends to strive to develop human capital, language barriers and cultural differences. Since cheap Chinese labor is often used, large industrial projects rarely transfer skills to the local African population.

\subsubsection{Institutions:}

Evidence shows that Nigeria is dramatically below average, despite strong revenues from expensive oil exports. Various bureaucratic obstacles and a lack of strong institutions have led to limited progress in infrastructure, agriculture and technology transfer. Similarly, major corruption has not transferred wealth to the lower classes and suppressed foreign direct investment in a sector other than oil. While Nigeria can develop credible, accountable and transparent institutions, it is unlikely that a free market system will emerge that promotes investment, diversification and competition.

4.2.5 Business:

Of all the variables leading to sustainable economic growth, the talks show that great progress has been made in the development of Nigerian entrepreneurs. Some Nigerian entrepreneurs have learned to perform successfully using Chinese models and have benefited from partnerships in joint ventures with the Chinese. However, linguistic and cultural barriers have led to a relatively small and educated elite being the main beneficiaries.

\subsection{CONCLUSIONS AND RECOMMENDATION}

\subsection{Conclusions}

Nigeria's biggest development problem is the lack of infrastructure with enormous investment needs. In addition, China has developed one of the world's largest and most competitive construction industry, with expertise in civilian work that is essential for the development of infrastructure, and its ability to provide the necessary financial support to countries in need of assistance, including Nigeria. On the other hand, China's industrialization efforts and massive inflow of foreign direct investment (FDI) into countries have led to a rapidly growing production economy that needs oil and mineral resources, which transcend its domestic resource and should therefore manage them from overseas, including Nigeria, which is well endowed with these resources. The short-term and long-term assessment of bilateral trade between China and Nigeria also shows positive trends, while the estimated short-term coefficient is not positively related to Nigerian economic growth, such as the long-term coefficient. However, there are certainly opportunities for Nigeria to gain China's growing influence; Nigerians are not fully capitalizing 
on the potential benefits. Much more needs to be done to expand policy-making, institution-building, human capital, entrepreneurship and the capacity of culture and leadership to maximize profits. Most importantly, Nigeria must develop a comprehensive strategy that better balances China's engagement, uses its own power and develops a sustainable development plan that appeals to its citizens.

\subsection{Recommendation}

Nigeria's first priority is to develop the ability to better manage its own policies in the face of China's commitment. Nigeria must recognize that China's commitment offers a unique opportunity to significantly expand its development and formulate a comprehensive strategy to meet its long-term needs. The Nigerian Government should avoid short-term repairs and predetermined agreements with the Chinese and go beyond agreements that target exclusively the oil sector.

Most importantly, there must be transparent oversight, largely overseen by the large middle classes. Given that the large middle class depends on sustainable economic growth, it will take some time to build reliable institutions, but small steps can be taken. One of the most important elements of institution-building is the promotion of civil society organizations and social enterprises, which enables the creation of market-based institutions, transparent and responsible budgetary management and monitoring mechanisms.

Whether they have learned anything from the experience of the U.S. is unclear, but Nigerians will certainly have a great deal of Western expertise in better managing difficult economic relations and how to protect key sectors of the economy from foreign competition, which Nigerians should be pragmatic about as they try to build "institutions."" This process is evolutionary and depends on political will and strong leadership to make the necessary changes.

Finally, in order to meet all these important needs, Nigerians must use their talents by bringing together top officials, scientists, entrepreneurs and civil society representatives to form a committee that brings out ideas to optimize western China's participation. At the same time, an interspecified implementation committee, consisting of the Ministries of Foreign Affairs, Industry, Trade, Agriculture and Investment, should be set up to limit all protocols by means of a critical analysis of action plans overseeing civil society.

\section{REFERENCES}

Aganga, O. (2013). Investment Opportunities in the Upstream and Downstream Sectors of the Oil and Gas Industry, Second Edition of the Nigeria Oil and Gas Investment Forum, Onne Oil and Gas Free Zone, Rivers State.

Anyanwu, J. C. (1993). Monetary Economics: Theory, Policy and Institutions. Onitsha: Hybrid Publishers.

Adam and Tweneboah (2009) "Foreign Direct Investment and Stock Market Development: Ghana's Evidence", International Research Journal of Finance and Economics Vol.26, Pp.1450-2887

Aremu, J. A. (2003). National Centre for Economic Management and Administration, Macro-economic Policy Analysis and Management Program, designed for Research Staff of the Central Bank of Nigeria.

Barro, R. J. (1991). Economic Growth in a Cross Section of Countries. Quarterly Journal of Economics. 106 (2), $407-443$

Balasubramanyan, V.N. (2001). Foreign Direct Investment in Developing Countries: Determinants and Impact. OECD Global Forum on International Investment.

Grossman, H. E. Helpman (1991). Innovation and Growth in the Global Economy. Cambridge: MIT Press

Moosa, I. A., (2002), Foreign Direct Investment - Theory, Evidence and Practice. Palgrave, New York. Anthony Rowe Limited.

Romer, P. (1990). —Endogenous Technological Changell. Journal of Political Economy, 98(5), 71-103.

OECD (1996), OECD Benchmark Definition of Foreign Direct Investment - Third Edition. Paris; Organization For Economic Co-Operation and Development Retrieved July 3, 2020 from Http:/Www.Oecd.Org/ Dataoecd/10/ 16/2090148.Pdf (Accessed 2nd July, 2020).

Umah, K.E (2007). The Impact of Foreign Private Investment on Economic Development of Nigeria. Nigeria Journal of Economics and Financial Research. 1 (3)

Wikipedia (2014). Foreign Direct Investment (FDI). Retrieved On July 3, 2020 from: Wikipedia, The Free Encyclopedia Available At: Http://Www.Ask.Com/Wiki/Foreign Direct Investment 